\title{
Lower Extremity Marjolin's Ulcer Reconstruction With Free Anterolateral Thigh Flap: A Case Series of 11 Patients
}

Shobhit Sharma ${ }^{1}$, Nikhil Das ${ }^{2}$, Vivek Gupta ${ }^{3}$, Sudipta Bera ${ }^{4}$, Navneeta Bisht ${ }^{5}$

1. Surgery, Shri Ram Murti Smarak Institute of Medical Sciences, Bareilly, IND 2. Surgery, Sapthagiri Institute of Medical Sciences and Research Centre, Bengaluru, IND 3. Plastic and Reconstructive Surgery, Sir Ganga Ram Hospital, New Delhi, IND 4. Plastic and Reconstructive Surgery, Institute of Medical Sciences, Banaras Hindu University, Varanasi, IND 5. Anaesthesiology, Shri Ram Murti Smarak Institute of Medical Sciences, Bareilly, IND

Corresponding author: Sudipta Bera, sudiptacnmc@gmail.com

\section{Abstract \\ Background}

Marjolin's ulcer (MU) of lower extremities usually presents with scar contracture and functional disability. They often follow an aggressive course and poor outcome, and require early radical removal. Split-thickness skin grafts, local flaps, or amputation are commonly practiced surgical options for MU. Though free flaps are gaining popularity for various oncoplastic reconstruction, they are not frequently used for MU. A free anterolateral thigh (ALT) flap may have a beneficial role as it provides simultaneous coverage for a large defect after radical tumor and scar excision.

\section{Methods}

Between January 2015 and December 2018, 11 patients with lower limb MU reconstructed with free ALT flap were reviewed retrospectively for the surgical procedure, recurrences, and functional outcomes.

\section{Results}

Mean dimensions of the defect and flaps were $8 \mathrm{~cm} \times 6 \mathrm{~cm}$ and $18.91 \mathrm{~cm} \times 11 \mathrm{~cm}$, respectively, and total flap coverage was obtained in nine cases. Marginal flap loss was noted in one and residual contracture in two cases. Functional improvement of the limb was achieved in all cases. Recurrence or disease-related mortality was not seen in any patient after a mean follow-up of 35.82 months.

\section{Conclusions}

Free ALT flap reconstruction of MU of extremity facilitates most radical tumor and scar-contracture removal and thus reduces the chances of re-ulceration. It facilitates local radiotherapy protocol with the provision of immediate durable coverage. Thus, it has a beneficial role other than a secondary reconstructive procedure. Moreover, an added benefit may be obtained with a "flow-through' flap" to avoid amputation and improve functional outcomes.

Review began 09/25/2020 Review ended 11/09/2020 Published 11/09/2020

\section{๑) Copyright 2020}

Sharma et al. This is an open access article distributed under the terms of the Creative Commons Attribution License CC-BY 4.0., which permits unrestricted use, distribution, and reproduction in any medium, provided the original author and source are credited.
Categories: Plastic Surgery, General Surgery, Oncology

Keywords: lower extremity, flow-through flap, reconstruction, anterolateral thigh (alt) flap, marjolin's ulcer, free alt flap

\section{Introduction}

Marjolin's ulcer (MU) is an infrequently encountered malignancy, occurring in a previous scar and commonly seen in the lower extremity. Post-burn scar or non-healing ulcers on lower extremity are particularly susceptible to MU as they are subjected to continuous stretching during daily movement $[1,2]$. MUs usually present with squamous cell carcinoma (SCC) in the milieu of a scar and deep-seated contracture, restriction of major joint movement, and functional disability. The outcome of extremity MU is negatively implicated due to a high chance of advanced disease, aggressive course, recurrence, functional loss, and amputations [2-6].

Wide local excision (WLE) and resurfacing with split-thickness skin graft (STSG), local flaps, or amputation are commonly practiced for the surgical management of extremity MU. The particular concern for MU surgery is the amount of tissue resection. By convention, a 2- to 5-cm margin clearance is recommended for MU [7-9]. But for extremity MU, plane and margin of resection are often not very evident due to the presence of concomitant deep-seated scar, contracture, and three-dimensional tissue involvement. Simultaneous contracture release and complete removal of the potential scar necessitates a greater amount of tissue to resurface the defect. Residual scar tissue leads to the persistent functional disability and the chance of reulceration. On the other hand, aggressive resection leads to the exposure of vital structures and may lead to 
an amputation. A free flap may have a beneficial role as it addresses simultaneous contracture release with radical scar excision and resurfacing of exposed vital structures.

We present here a series of 11 cases of lower extremity MU resurfaced with free anterolateral thigh (ALT) flaps and their outcome analysis over the last five years.

\section{Materials And Methods}

All patients with post-burn lower extremity MU reconstructed with free ALT flap between January 2015 and December 2019 were reviewed retrospectively in this study. The study was conducted after clearance from the Institutional Ethical Board and as per standard ethical guidelines. Informed written consent was obtained from each patient for the utilization of the data for the study purpose. Patient-related variables were collected from the hospital database.

Patients attending the Outpatient Department with a history of ulcer or lesion over a long-standing scar, a recurrent ulcer on previous scar tissue, or a non-healing ulcer of an old burn injury of the lower extremity were identified. A wedge biopsy of the lesion was performed to confirm the diagnosis of MU. The dimension of the lesion was noted, and regional lymph nodes (LNs) were assessed clinically. The degree of contracture was noted in case of major joint involvement. Pre-operative MRI of the lesion was performed to note the deeper extent of the lesion. Written informed consent for surgery was obtained from patients and attendants as per Institutional Protocol. WLE of the lesion with at least 2-cm margin with simultaneous contracture release by full-thickness excision of the scar was performed. The scar tissue was excised radically till the complete release of contracture or encountering neurovascular structure, bone, or joint. Margins were assessed with frozen section biopsy and re-excised if required before final reconstruction. All the defects were resurfaced with free ALT flap from the opposite limb irrespective of the dimension. Removal of the involved segment of vessels was performed and considered for a 'flow-through' ALT flap reconstruction in case of perivascular involvement. The flap donor site and the residual defect was skin grafted. Regional LN sampling or dissection was performed whenever palpable.

Post-operative radiotherapy was given in larger lesions $(>10 \mathrm{~cm})$, in margin positive cases after a re-excision, and high-grade tumor on histopathological examination (HPE). Patients were followed up with a periodic assessment of recurrence and functional recovery. Suspicious lesions were sent for HPE. Ranges of active and passive joint movements, residual re-contracture, and limb length discrepancy were evaluated.

All results were tabulated, and statistical analysis was performed using GraphPad Prism version 8.0.0 software (GraphPad Software, San Diego, CA, USA).

\section{Results}

In our study, nine patients were male and two were female. The mean age of the patients was 54.27 years. On HPE, a well-differentiated SCC was noted in nine patients, and moderately differentiated SCC was noted in two patients. The mean dimensions of ulcer and flap were $8 \mathrm{~cm} \times 6 \mathrm{~cm}$ and $18.91 \mathrm{~cm} \times 11 \mathrm{~cm}$, respectively. One of the 11 free ALT flaps was a 'flow-through' flap. The posterior tibial artery was used as a recipient vessel in most of the cases (9/11). The femoral and popliteal artery was used in one case each (Figure 1). Inguinal LN dissection was performed in two cases, which came to be negative in both. The flap donor site was skin grafted in all cases (Figure 2 and Table 1 ). 


\section{Cureus}

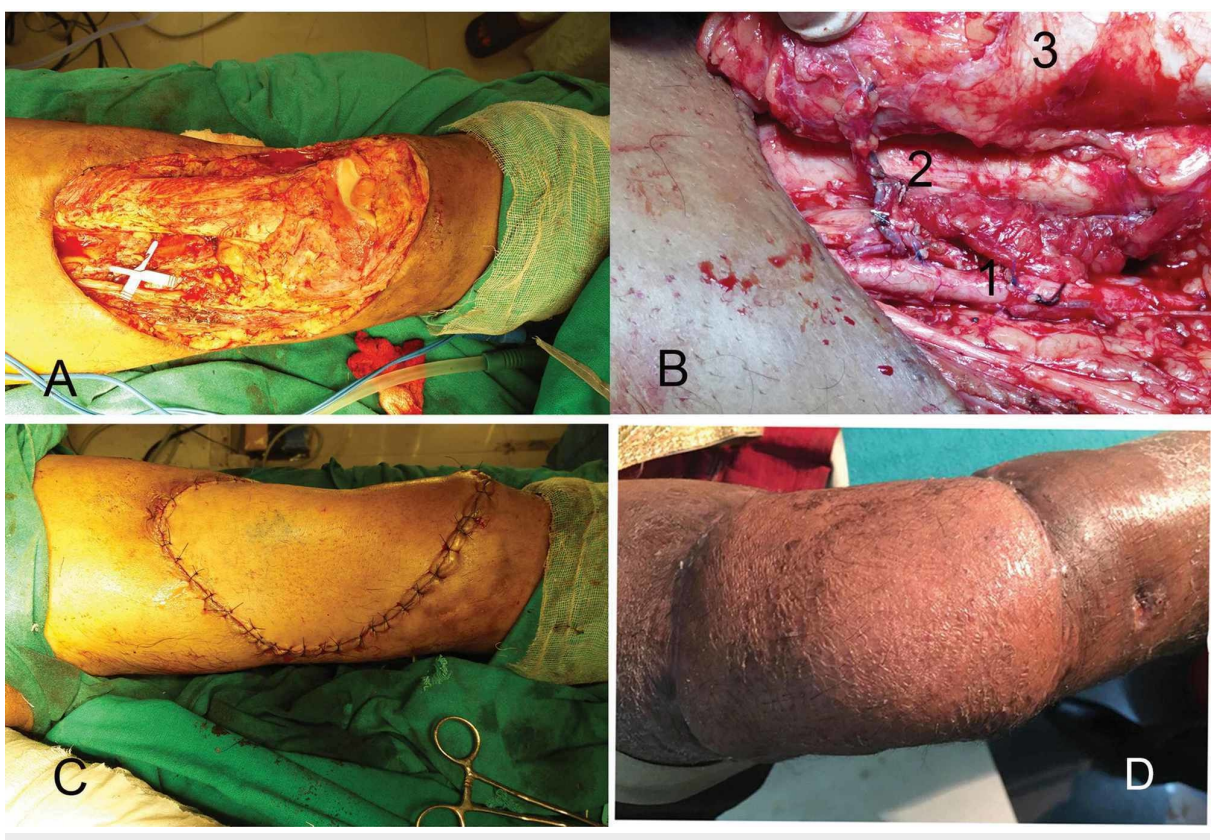

FIGURE 1: Case 7: Marjolin's ulcer of thigh demonstrating microvascular anastomosis.

(A) Wide local excision defect with exposed femur and knee joint. (B) Microvascular anastomosis (1, femoral artery; 2, lateral circumflex femoral artery perforator). (C) Flap inset. (D) Three-year follow-up showing a wellsettled flap. 


\section{Cureus}
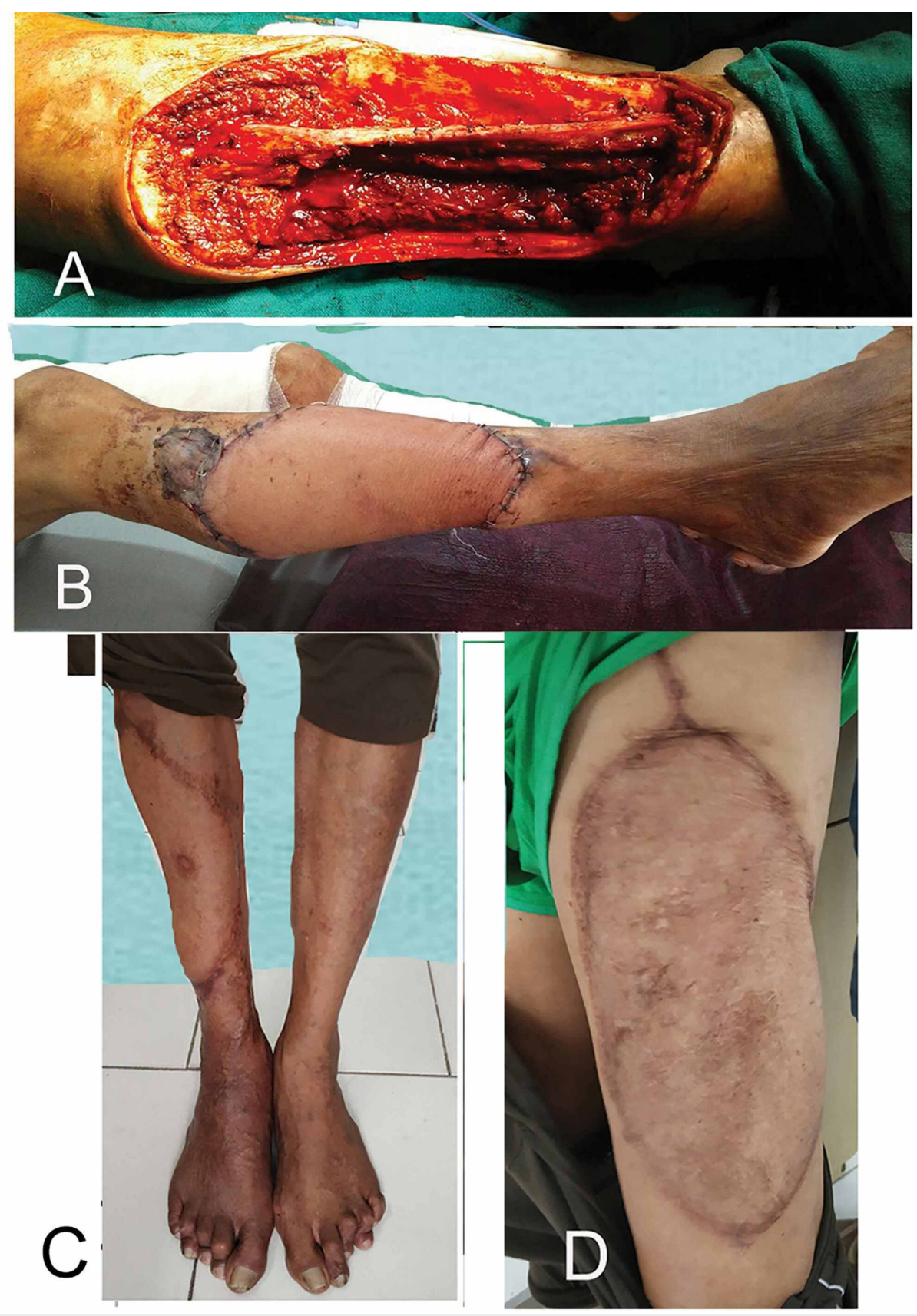

FIGURE 2: Case 1: Marjolin's ulcer of the leg with three-year follow-up of flap donor and recipient site.

(A) Wide local excision showing exposed tibia, muscles, and the neurovascular structure of the anterior compartment of the leg. (B) Post-operative picture showing free ALT flap and skin graft at the upper margin. (C \& D) Three-year follow-up picture of the flap and donor site on the contralateral thigh. 


\section{Cureus}

\begin{tabular}{|c|c|c|c|c|c|c|c|c|}
\hline $\begin{array}{l}\text { Case } \\
\text { no }\end{array}$ & Age/sex & Location & $\begin{array}{l}\text { Pre-operative } \\
\text { contracture }\end{array}$ & $\begin{array}{l}\text { Dimension } \\
\text { of ulcer }\end{array}$ & Defect after excision & Treatment & $\begin{array}{l}\text { Flap } \\
\text { dimension }\end{array}$ & $\begin{array}{l}\text { LN } \\
\text { dissection }\end{array}$ \\
\hline 1 & $60 / \mathrm{M}$ & Leg & $60^{\circ}$ & $\begin{array}{l}10 \mathrm{~cm} \times 8 \\
\mathrm{~cm}\end{array}$ & Exposed tendon and tibia & $\begin{array}{l}\text { Free ALT and } \\
\text { STSG }\end{array}$ & $\begin{array}{l}28 \mathrm{~cm} \times \\
17 \mathrm{~cm}\end{array}$ & No \\
\hline 2 & $30 / \mathrm{M}$ & Leg & $20^{\circ}$ & $\begin{array}{l}10 \mathrm{~cm} \times 8 \\
\mathrm{~cm}\end{array}$ & Exposed tendon & Free ALT & $\begin{array}{l}20 \mathrm{~cm} \times \\
10 \mathrm{~cm}\end{array}$ & No \\
\hline 3 & $55 / \mathrm{M}$ & knee & $90^{\circ}$ & $4 \mathrm{~cm} \times 4 \mathrm{~cm}$ & $\begin{array}{l}\text { Exposed knee joint and femur, } \\
\text { perivascular adhesion }\end{array}$ & $\begin{array}{l}\text { Free (flow- } \\
\text { through) ALT }\end{array}$ & $\begin{array}{l}25 \mathrm{~cm} \times \\
15 \mathrm{~cm}\end{array}$ & No \\
\hline 4 & $71 / \mathrm{M}$ & Knee & $60^{\circ}$ & $6 \mathrm{~cm} \times 4 \mathrm{~cm}$ & Exposed tendon & Free ALT & $\begin{array}{l}15 \mathrm{~cm} \times 8 \\
\mathrm{~cm}\end{array}$ & No \\
\hline 5 & $38 / F$ & Knee & $60^{\circ}$ & $\begin{array}{l}10 \mathrm{~cm} \times 6 \\
\mathrm{~cm}\end{array}$ & $\begin{array}{l}\text { Exposed neurovascular structure } \\
\text { and joint }\end{array}$ & Free ALT & $\begin{array}{l}15 \mathrm{~cm} \times \\
10 \mathrm{~cm}\end{array}$ & ILND \\
\hline 6 & $60 / F$ & Ankle & $20^{\circ}$ & $4 \mathrm{~cm} \times 4 \mathrm{~cm}$ & Exposed tendons & Free ALT & $\begin{array}{l}15 \mathrm{~cm} \times 6 \\
\mathrm{~cm}\end{array}$ & No \\
\hline 7 & $78 / \mathrm{M}$ & Thigh & No & $\begin{array}{l}10 \mathrm{~cm} \times 10 \\
\mathrm{~cm}\end{array}$ & Exposed bone (femur) and joint & Free ALT & $\begin{array}{l}25 \mathrm{~cm} \times \\
15 \mathrm{~cm}\end{array}$ & ILND \\
\hline 8 & $48 / \mathrm{M}$ & Knee & $20^{\circ}$ & $4 \mathrm{~cm} \times 4 \mathrm{~cm}$ & Exposed popliteal artery & Free ALT & $\begin{array}{l}15 \mathrm{~cm} \times \\
10 \mathrm{~cm}\end{array}$ & No \\
\hline 9 & $52 / \mathrm{M}$ & Knee & $30^{\circ}$ & $4 \mathrm{~cm} \times 4 \mathrm{~cm}$ & Exposed tendon & Free ALT & $\begin{array}{l}15 \mathrm{~cm} \times \\
10 \mathrm{~cm}\end{array}$ & No \\
\hline 10 & 45/M & Knee & $20^{\circ}$ & $2 \mathrm{~cm} \times 2 \mathrm{~cm}$ & Exposed tendon & Free ALT & $\begin{array}{l}15 \mathrm{~cm} \times \\
10 \mathrm{~cm}\end{array}$ & No \\
\hline 11 & $60 / M$ & Leg & $20^{\circ}$ & $8 \mathrm{~cm} \times 4 \mathrm{~cm}$ & Exposed tendon & $\begin{array}{l}\text { Free ALT and } \\
\text { STSG }\end{array}$ & $\begin{array}{l}20 \mathrm{~cm} \times \\
10 \mathrm{~cm}\end{array}$ & No \\
\hline
\end{tabular}

TABLE 1: Surgical details of free flap surgery.

ALT, anterolateral thigh; ILND, inguinal lymph node dissection; LN, lymph node; STSG, split-thickness skin graft

Flap surgery was successful in all. Marginal flap loss was seen in one case, which was debrided and later skin grafted. The mean follow-up period was $35.82 \pm 2.09$ months. Partial contracture persisted in two cases within the follow-up period (Figure 3). 


\section{Cureus}

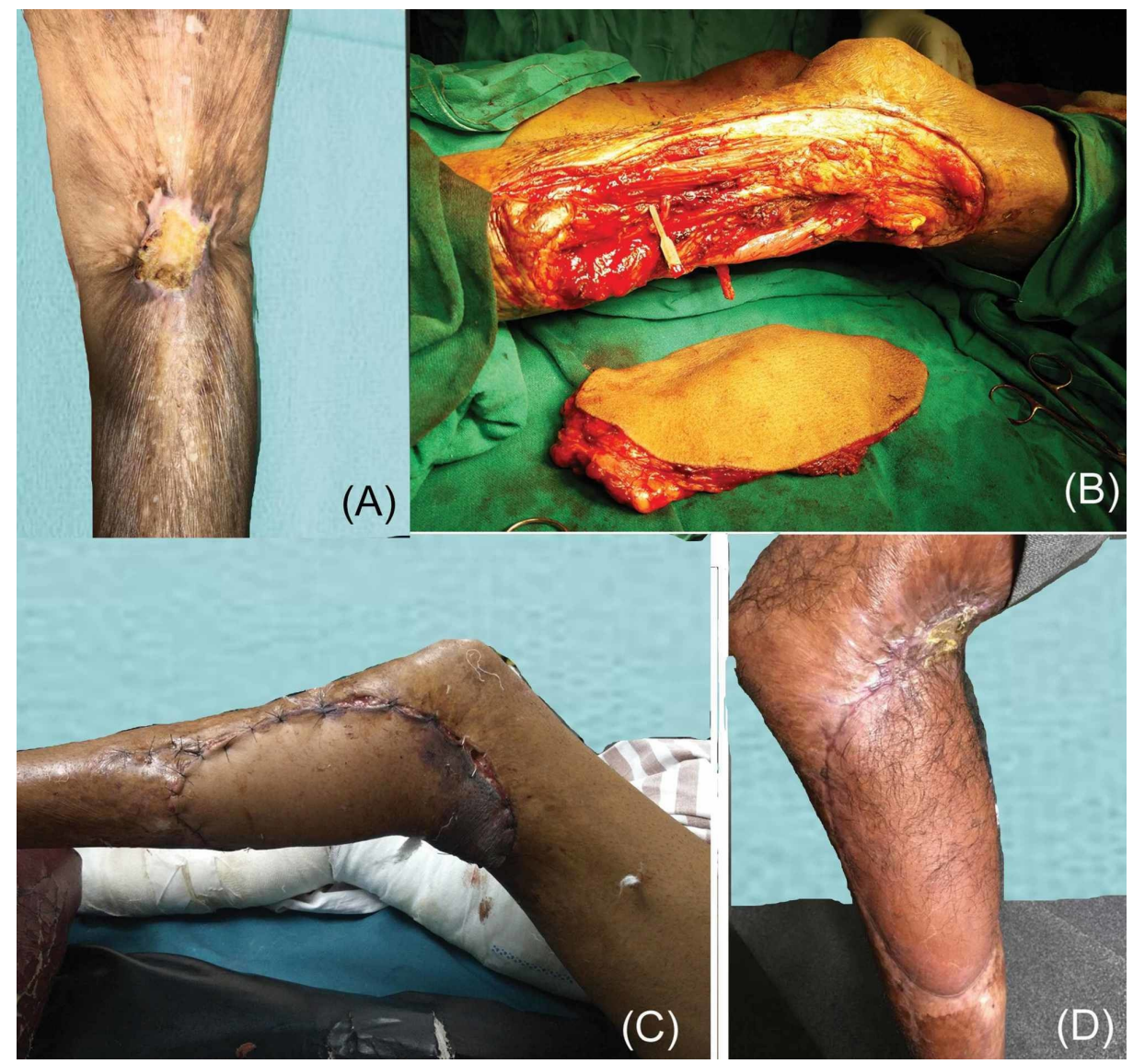

FIGURE 3: Case 3: Marjolin's ulcer of the knee joint and upper leg with severe contracture.

(A) Ulcerative lesion over the back of the knee. (B) Wide local excision defect of the lesion and harvested (25 $\mathrm{cm} \times 15 \mathrm{~cm}$ ) ALT flap. (C) First week follow-up picture. Marginal flap necrosis and residual contracture were noted. (D) Residual contracture but well-settled flap.

ALT, anterolateral thigh

Re-contracture was not seen in any of the cases. The limb function was improved in all cases. Complete weight-bearing was achieved in all cases. In five cases, postoperative radiotherapy was given due to a larger size. No recurrence or disease-related mortality was noted within the follow-up period (Table 2). 


\section{Cureus}

\begin{tabular}{|c|c|c|c|c|c|c|}
\hline $\begin{array}{l}\text { Case } \\
\text { no }\end{array}$ & Flap-related complications & Radiotherapy & $\begin{array}{l}\text { Contracture at } \\
24 \text { months }\end{array}$ & $\begin{array}{l}\text { Limb discrepancy } \\
\text { at } 24 \text { months }\end{array}$ & Recurrence & $\begin{array}{l}\text { Follow-up period } \\
\text { (months) }\end{array}$ \\
\hline 1 & None & Yes & No & No & No & 48 \\
\hline 2 & None & Yes & No & No & No & 42 \\
\hline 3 & $\begin{array}{l}\text { Marginal flap loss, debrided } \\
\text { and skin grafted }\end{array}$ & Yes & $25^{\circ}$ & $2 \mathrm{~cm}$ & No & 42 \\
\hline 4 & None & No & $20^{\circ}$ & $2 \mathrm{~cm}$ & No & $\begin{array}{l}\text { Lost in follow-up after } \\
30 \text { months }\end{array}$ \\
\hline 5 & None & Yes & $10^{\circ}$ & $1 \mathrm{~cm}$ & No & 40 \\
\hline 6 & None & No & No & No & No & 36 \\
\hline 7 & None & Yes & Arthrodesis & No & No & 36 \\
\hline 8 & None & No & No & No & No & 36 \\
\hline 9 & None & No & No & No & No & $\begin{array}{l}\text { Death unrelated to } \\
\text { disease after } 30 \\
\text { months }\end{array}$ \\
\hline 10 & None & No & No & No & No & 30 \\
\hline 11 & None & No & No & No & No & 24 \\
\hline
\end{tabular}

TABLE 2: Follow-up and outcomes of the surgery.

\section{Discussion}

MU is a rare malignancy arising from post-traumatic scar described by French physician Jean-Nicholas Marjolin in 1828. The term 'Marjolin ulcer' was coined by Da Costa to describe the malignancy of post-burn scar tissue [10]. Skin breakdown on chronic scars, chronic unhealed ulcers, continuous irritation, secondary intention healing, diminished vascularity, immunity, repeated trauma, and chronic infections of an ulcer are commonly implicated for the development of MU [10-11]. MU of extremities commonly occurs near major joints as these places are subjected to repeated stretching and friction during daily activities. The patients usually present with functional limitations along with ulcers on a deep-seated scar and severe contracture. Extremity is probably the location of the most aggressive form of MU [2-6]. Surgical removal early in the course of the tumor is the mainstay of management, though newer modalities such as cryosurgery, intralesional interferons, 5-fluorouracil or methotrexate, and photodynamic therapy are described without much established definitive role [12]. The outcome of the metastatic disease is very poor, and surgical management and/or chemoradiotherapy have limited benefits other than palliation.

WLE with a 2-cm margin is accepted in most of the recent studies. Resurfacing with a skin graft, local and regional flaps are commonly practiced surgical modalities after the radical excision of MU. Alternatively, an amputation or disarticulation is also a rational approach in advanced MU [3-4,13-14]. The free flap is usually reserved to resurface a larger lesion if a sufficient amount of local tissue is not available.

As per conventional belief, the scar tissue provides a barrier to the spread of the disease. But once the barrier is breached by the ulcer, it is prone to lymphatic spread and distant metastasis. But now it is assumed that malignant cells skip immunological detection by the altered physiological function of the scar tissue. These cells are more prone to metastasis and aggressive malignant transformations [3,15-16]. Metastasis is regarded as the most important prognostic factor [11,15]. In lower limb MU, the ulcer is usually deep-seated at presentation due to repeated cycle of ulcer and secondary intention healing subjecting to persistent searing force on ulcer, and reconstructive need is much beyond the two-dimensional WLE defect. Free flaps are emerging as routine oncoplastic reconstruction for various malignancies. Free latissimus dorsi (LD) flap has been described for reconstruction of MU of scalp earlier [1,10]. Aydogdu et al. also mentioned the use of free flap in their series of surgical reconstruction of MU of different anatomical locations. Though they doubted the radical scar clearance as it removes the protective barrier to the spread of the disease, they recommended the beneficial role of radical tissue clearance for the early-stage disease [17]. Bozkurt et al. recommended the use of free flap in initially skin-grafted and recurrence-free patients as a secondary procedure [18]. Al Maksoud et al. described the use of free LD muscle flap for MU of weight-bearing heel [19]. But, in a background of usually aged and debilitating patient, free flap reconstruction remains much a matter of individual expertise, judgment, and preference. 
In our experience, scar contracture in MU is usually deep-seated than the two-dimensional scar and tumor. Due to persistent inflammatory components, the deeper muscle and neurovascular structures are usually seen fibrosed, and three-dimensional WLE excision remains very difficult. Unlike ordinary post-burn contracture, contracture encountered along with MU involves deeper tissue diffusely. It does not have a definite tissue layer of excision and often involves all tissue layers around the neurovascular bundle and tendon. Tendon and neurovascular shortening is not very rare also. High incidence of MU around the knee and vascular shortening is a prominent feature in extremity MU. The reconstructive procedure with other than a free flap could not eliminate contracture optimally, and often amputation remains a safe alternative. The provision of a free flap in pre-operative planning helps an uncompromised radical excision of the lesion as well as scar and contracture tissue. In this way, a free flap improves limb function. Besides, this adds a substantial amount of tissue and reduces residual searing force. As a repeated episode of ulceration and healing due to persistent stretching of scar believes to be prone to malignant degeneration of scar, a free flap may have a beneficial role to prevent re-ulceration of the previous reconstruction, even if it partially covers a large defect. In our cases, the mean dimension of the flap was $18.91 \mathrm{~cm} \times 11 \mathrm{~cm}$, which was approximately 2.59 times larger than the two-dimensional defect after tumor excision with a 2-cm margin. No re-ulceration was noted in a partial free flap and skin graft reconstruction in the cases in our series.

The beneficial role of radiotherapy has been established as an adjuvant treatment in large lesions $(>10 \mathrm{~cm})$, margin positive cases, or recurrences by the earlier studies [13-14,17]. As a free flap improves local radiation tolerance than a skin graft reconstruction, an ALT flap adds value to the use of free flap as immediate reconstructive means rather than secondary reconstruction [18]. A free ALT flap does not add much operative morbidity as the whole surgery can be performed only under spinal anesthesia or epidural analgesia in the same sitting, as we have observed in our series.

Free ALT flap also adds its value with a provision of 'follow-through' flap, which is popular for limb salvage for vascular injuries in trauma [20,21]. In our study, vascular reconstruction is performed along with resurfacing with such means in one case. The amputation was avoided even after an unexpected intraoperative finding of vascular tethering. Thus, a free ALT flap may be value-added in similar cases.

\section{Conclusions}

Free ALT flap reconstruction of MU of extremity facilitates most radical tumor and scar-contracture removal and thus reduces chances of re-ulceration. It facilitates local radiotherapy protocol with the provision of immediate supple coverage, and thus has a beneficial role other than a secondary reconstructive procedure. Moreover, added benefit may be obtained with a 'flow-through' flap to avoid amputation and improve functional outcome.

This was a small case series from a single institute, and outcome analysis on a larger population was beyond the scope due to the infrequent occurrence of MU. Evidence from multiple studies may be necessary to ascertain the role of a free flap for extremity MU reconstruction.

\section{Additional Information \\ Disclosures}

Human subjects: Consent was obtained by all participants in this study. Institutional Ethical Board of Shri Ram Murti Smarak Institute of Medical Sciences, Bareilly, India issued approval SRMSIMS/ECC/2020-21/008. Animal subjects: All authors have confirmed that this study did not involve animal subjects or tissue. Conflicts of interest: In compliance with the ICMJE uniform disclosure form, all authors declare the following: Payment/services info: All authors have declared that no financial support was received from any organization for the submitted work. Financial relationships: All authors have declared that they have no financial relationships at present or within the previous three years with any organizations that might have an interest in the submitted work. Other relationships: All authors have declared that there are no other relationships or activities that could appear to have influenced the submitted work.

\section{References}

1. Atiyeh BS, Hayek SN, Kodeih MG: Marjolin's ulcer of the scalp: a reconstructive challenge . Ann Burns Fire Disasters. 2005, 18:197-201.

2. Chalya PL, Mabula JB, Rambau P, et al.: Marjolin's ulcers at a university teaching hospital in Northwestern Tanzania: a retrospective review of 56 cases. World J Surg Oncol. 2012, 10:38. 10.1186/1477-7819-10-38

3. Kerr-Valentic MA, Samimi K, Rohlen BH, Agarwal JP, Rockwell WB: Marjolin's ulcer: modern analysis of an ancient problem. Plast Reconstr Surg. 2012, 123:184-191. 10.1097/PRS.0b013e3181904d86

4. Pekarek B, Buck S, Osher L: A comprehensive review on Marjolin's ulcers: diagnosis and treatment . J Am Col Certif Wound Spec. 2011, 3:60-64. 10.1016/j.jcws.2012.04.001

5. Tiftikcioglu YO, Ozek C, Bilkay U, Uckan A, Akin Y: Marjolin ulcers arising on extremities . Ann Plast Surg. 2010, 64:318-320. 10.1097/sap.0b013e3181a73064

6. Tobin C, Sanger JR: Marjolin's ulcers: a case series and literature review . Wounds: Compendium Clin Res Pract. 2014, 26:248-254.

7. Copcu E: Marjolin's ulcer: a preventable complication of burns? . Plast Reconstr Surg. 2009, 124:156. 10.1097/PRS.0b013e3181a8082e 
8. Asuquo M, Ugare G, Ebughe G, Jibril P: Marjolin’s ulcer: the importance of surgical management of chronic cutaneous ulcers. Int J Dermatol. 2007, 46:29-32. 10.1111/j.1365-4632.2007.03382.X

9. Copcu E, Aktas A, Sismant N, Oztant Y: Thirty-one cases of Marjolin's ulcer. Clin Exp Dermatol. 2003, 28:138-141. 10.1046/j.1365-2230.2003.01210.x

10. Daya M, Balakrishan T: Advanced Marjolin's ulcer of the scalp in a 13-year-old boy treated by excision and free tissue transfer: case report and review of literature. Indian J Plast Surg. 2009, 42:106-111. 10.4103/0970-0358.53020

11. Yu N, Long X, Lujan-Hernandez JR, et al.: Marjolin's ulcer: a preventable malignancy arising from scars . World J Surg Oncol. 2013, 11:313. 10.1186/1477-7819-11-313

12. Chlihi A, Bouchta A, Benbrahim A, Bahechar N, Boukind EH: Marjolin's ulcer, destiny of an unstable scar. About 54 cases of burns sequelae. Ann Chir Plast Esthet. 2002, 47:291-297. 10.1016/s0294-1260(02)00120-6

13. Hassan SA, Cheatle TR, Fox JA: Marjolin's ulcer: a report of three cases and review of literature . Phlebology. 1993, 8:34-36. 10.1177/026835559300800110

14. Challa VR, Deshmane V, Reddy MBA: A retrospective study of Marjolin's ulcer over an eleven year period . J Cutan Aesthet Surg. 2014, 7:155. 10.4103/0974-2077.146667

15. Bazaliński D, Przybek-Mita J, Barańska B, Więch P: Marjolin's ulcer in chronic wounds - review of available literature. Contemp Oncol (Pozn). 2017, 21:197-202. 10.5114/wo.2017.70109

16. Bostwick J 3rd, Pendergrast WJ Jr, Vasconez LO: Marjolin's ulcer: an immunologically privileged tumor? . Plast Reconstr Surg. 1976, 57:66-69.

17. Aydogdu E, Yildirim S, Akoz T: Is surgery an effective and adequate treatment in advanced Marjolin's ulcer? . Burns. 2005, 31:421-431. 10.1016/j.burns.2005.02.008

18. Bozkurt M, Kapi E, Kuvat SV, Ozekinic S: Current concepts in the management of Marjolin's ulcers: outcomes from a standardized treatment protocol in 16 cases. J Burn Care Res. 2010, 31:776-780. 10.1097/BCR.0b013e3181eed210

19. Al Maksoud AM, Barsoum AK, Moneer M: Squamous cell carcinoma of the heel with free latissimus dorsi myocutaneous flap reconstruction: case report and technical note. J Surg Case Rep. 2016, 2016:rjw067. 10.1093/jscr/rjw067

20. Koshima I, Kawada S, Etoh H, Kawamura S, Moriguchi T, Sonoh H: Flow-through anterior thigh flaps for one-stage reconstruction of soft-tissue defects and revascularization of ischemic extremities. Plast Reconstr Surg. 1995, 95:252-260. 10.1097/00006534-199502000-00004

21. Soutar DS, Scheker LR, Tanner NS, McGregor IA: The radial forearm flap: a versatile method for intra-oral reconstruction. Br J Plast Surg. 1983, 36:1-8. 10.1016/0007-1226(83)90002-4 